\title{
Transvenous Embolization of Dural Arteriovenous Fistulas of the Hypoglossal Canal: Report of Three Cases and Review of the Literature
}

\author{
Alejandro Santillan Justin Schwarz Athos Patsalides \\ Division of Interventional Neuroradiology, Department of Neurosurgery, New York \\ Presbyterian Hospital/Weill Cornell Medical Center, New York, NY, USA
}

\section{Keywords}

Embolization · Transvenous route $\cdot$ Hypoglossal canal arteriovenous fistula

\begin{abstract}
In this article, we report three cases of dural arteriovenous fistulas of the hypoglossal canal treated via transvenous approach. We also perform a review of the literature on the endovascular management of this type of lesions with particular attention to the dangerous extracranial-intracranial anastomoses that can occur at this level.

(C) 2018 S. Karger AG, Basel
\end{abstract}

\section{Introduction}

Intracranial dural arteriovenous fistulas (DAVFs) constitute only 5-15\% of all intracranial vascular malformations. DAVFs of the hypoglossal canal (HCDAVFs) represent an even rarer condition with an incidence of 3.6-5.1\% of all DAVFs [1-3]. A thorough knowledge of the anatomy of the venous system and dangerous extracranial-intracranial anastomosis is paramount for successful treatment.

\section{Case Reports}

Case 1

A 57-year-old left-handed man with past medical history of anxiety presented with left-sided pulsatile tinnitus and flushing sensation on his left ear for 6 months. Magnetic resonance angiography showed a large lesion obliterating the left jugular foramen that was concerning for glomus jugulare tumor. A diagnostic subtraction cerebral angiogram (DSA) showed a HCDAVF supplied by the neuromeningeal trunk from 
bilateral ascending pharyngeal arteries (APhAs), the clival branches of bilateral meningohypophyseal trunks (MHT), and the transmastoid branches of the left occipital artery (OA), and the anterior and posterior meningeal branches of the left vertebral artery (VA). The arteriovenous fistula connected to the left anterior condylar vein (ACV) which eventually drained into the left internal jugular vein (IJV), marginal sinus, and anterior internal vertebral venous plexus (AIVP) (Fig. 1a-c).

A selective catheterization of the left ACV via the left IJV allowed us to treat the fistula with coil embolization of the ACV. During the embolization, we attempted to access a small region of the ACV with a microcatheter by advancing further into the venous pouch. The microwire was advanced into the coil mass, and a selective venogram through the microcatheter showed a small amount of contrast extravasation beyond the pouch. Protamine was given immediately. The microcatheter was left in position, and the bleeding was stopped after an emergent injection of n-BCA glue. There was no further extravasation of contrast and the fistula was completely obliterated (Fig. 1d). MRI of the cervical spine obtained $6 \mathrm{~h}$ after the procedure demonstrated no epidural hematoma. The patient had immediate resolution of his pulsatile tinnitus and left ear flushing sensation. He remained neurologically intact except for a partial palsy of the left hypoglossal nerve. One month after embolization, the patient had significant improvement of his hypoglossal nerve palsy, and the tinnitus and flushing sensation had not recurred.

Case 2

A 54-year-old left-handed man with a history of Osler-Weber-Rendu syndrome initially experienced "beeping in his ears" and a sharp pain in the left ear after diving into water 2 years ago, with his symptoms resolving without intervention. Three weeks before presentation, the patient developed a new pulsatile whooshing sound in the left ear that progressively worsened, especially during activities, and was affecting his sleep. A DSA showed a HCDAVF supplied by the medial clival branches of the MHT bilaterally, the neuromeningeal trunks arising from bilateral APhAs, the transmastoid branches of the left OA, the posterior meningeal branch of the left VA and the anterior meningeal branch of the right VA. The arteriovenous fistula was connected to the left ACV vein which eventually drained into the left inferior petrosal sinus (IPS), the left IJV and the AIVP (Fig. 2a, b).

A selective catheterization of the left ACV via the left IJV was followed by coil embolization of the fistula via the left IJV. There was no significant residual arteriovenous shunt after the embolization. Immediately following embolization, the tinnitus and bruit resolved and the patient remained neurologically intact without cranial nerve deficits.

Case 3

A 67-year-old left handed female with past medical history of remote Hodgkin's lymphoma status after radiotherapy initially presented with an insidious-onset pulsatile tinnitus like a "whooshing" sensation on the left side greater than the right over the time course of 3 months. A magnetic resonance angiography demonstrated abnormal vessels in the left jugular fossa. DSA showed a HCDAVF supplied by bilateral APhAs, the left $\mathrm{OA}$, the left posterior auricular artery, the medial clival branch of the left internal carotid artery (ICA), and the posterior meningeal branch of the left VA. The fistula drained into the left ACV and deep cervical vein which were connected to the jugular bulb of bilateral IJVs (Fig. 3a, b). The left transverse sinus was not visualized entirely since there was some retrograde flow from the high-flow fistula coming from the right $\mathrm{APhA}$.

A selective catheterization of the left ACV via the right IJV was performed followed by coil embolization. Postembolization angiogram demonstrated complete occlusion of the HCDAVF with restoration of venous drainage into the left transverse/sigmoid sinus and IJV (Fig. 3c, d). The patient's tinnitus resolved completely, and a DSA performed at 6 months showed complete embolization of the fistula.

\section{Discussion}

Clinical Manifestations and Vascular Anatomy

The clinical manifestations associated with HCDAVFs depend on the pattern of the venous drainage. Symptoms include headaches [2, 4], tinnitus [2, 5-7], hypoglossal nerve palsy [2, 3, 8], bruit [1, 9], diplopia [6, 10], proptosis and chemosis [1, 4, 6, 9, 10], hoarseness [11], vocal cord palsy [11], intracranial hemorrhage [12], and congestion myelopathy [2, 12]. 


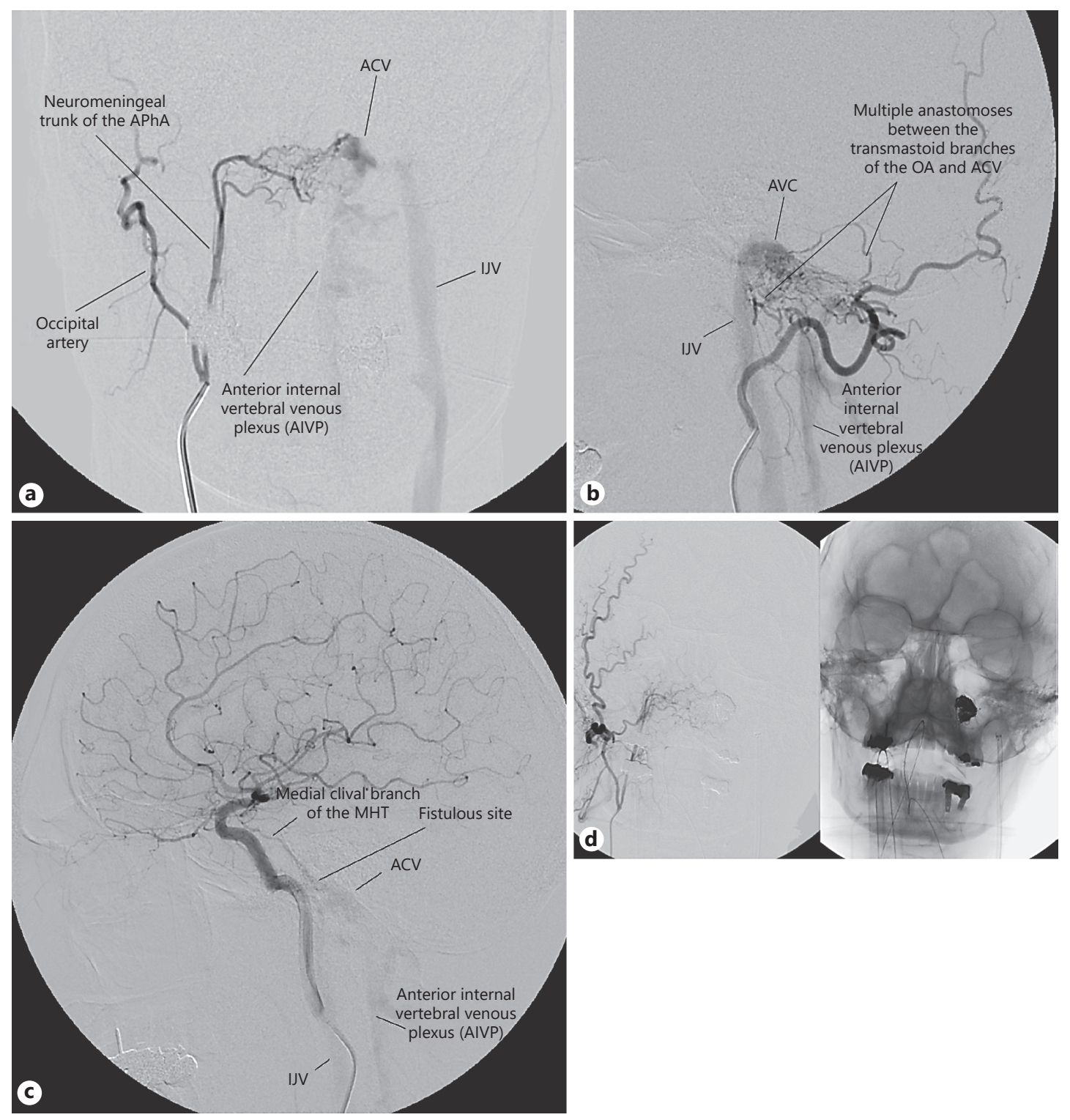

Fig. 1. a DSA in AP projection showing a HCDAVF supplied by the neuromeningeal trunk of the right APhA. The APhA and OA originate from a common trunk. The arteriovenous fistula is connected to the left ACV which eventually drains into the left IJV and AIVP. b DSA in lateral projection showing a HCDAVF supplied by transmastoid branches of the left OA that connects to the left ACV which eventually drains into the left IJV, and AIVP. c DSA in lateral projection showing a HCDAVF supplied by the medial clival branch of the MHT of the left ICA which is connected to the left ACV which eventually drains into the left IJV and AIVP. d DSA in AP projection of the right neuromeningeal trunk shows complete embolization of the fistula. The coil mass can be better visualized in the unsubtracted AP view.

The APhA has two major branches: the pharyngeal trunk which is extracranial, and the neuromeningeal trunk that enters the foramen magnum where it branches to supply the vasa nervorum of cranial nerves IX, X, XI, and XII. The neuromeningeal trunk has two main branches, the hypoglossal branch and the jugular branch. In rare instances, the neuromeningeal trunk may arise from the OA or even the posterior auricular artery such as in our first case presented where the right APhA arose directly from the OA (Fig. 1a). 


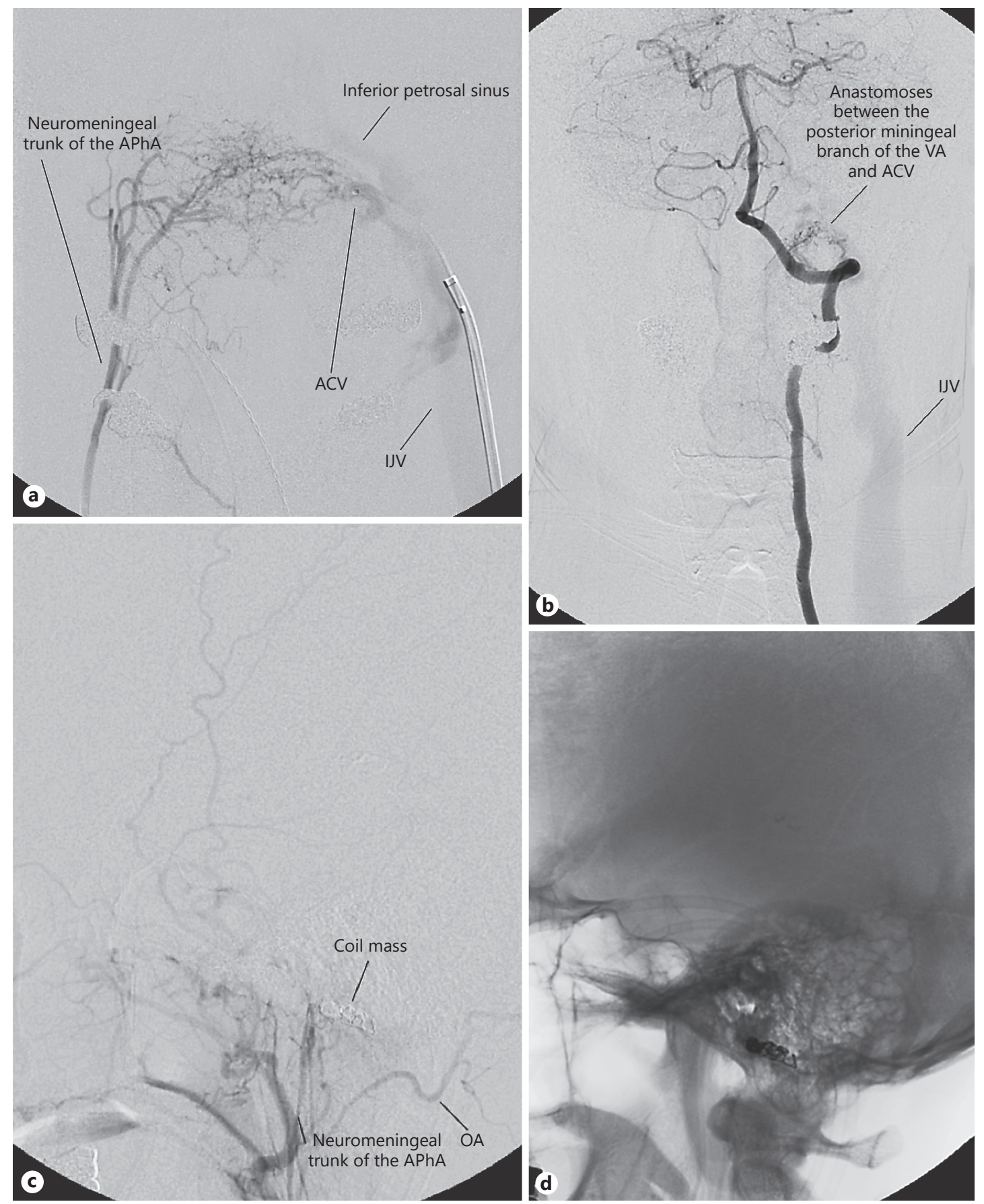

Fig. 2. a DSA in AP projection showing a HCDAVF supplied by the neuromeningeal trunks of the right APhA. The arteriovenous fistula is connected to the left ACV vein which eventually drains into the left inferior petrosal sinus and left IJV. b DSA in AP projection showing a HCDAVF supplied by the posterior meningeal branch of the left VA. The arteriovenous fistula is connected to the left ACV vein which eventually drains into the left IJV. c DSA in lateral projection from the neuromeningeal trunk of the left APhA shows complete embolization of the HCDAVF. $\mathbf{d}$ The coil mass is better seen on the unsubtracted view. 


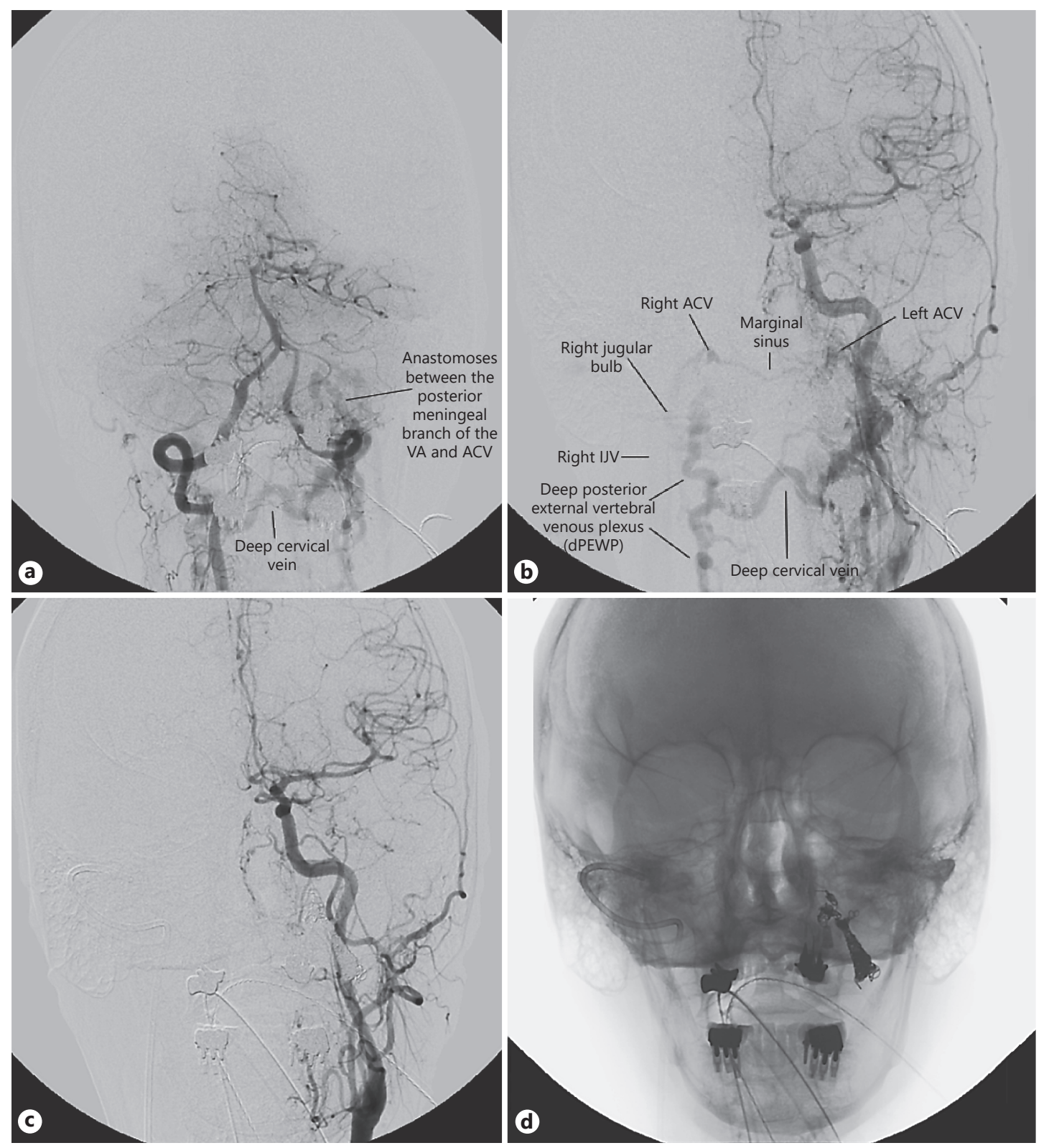

Fig. 3. a DSA in AP projection of the right VA shows a fistula supplied by the posterior meningeal branch of the left VA with venous drainage into the left ACV and deep cervical vein which are connected to the jugular bulb of bilateral IJVs. b DSA in AP projection from the left common carotid artery showing the venous drainage from this complex HCDAVF. The venous drainage includes bilateral ACVs, marginal sinus, deep cervical vein, and deep posterior external vertebral venous plexus that eventually drain into bilateral IJVs. c DSA in AP projection after embolization shows complete obliteration of the HCDAVF. $\mathbf{d}$ The coil mas is well seen in the unsubtracted AP view.

The hypoglossal canal contains the hypoglossal nerve, the neuromeningeal trunk of the $\mathrm{APhA}$, and the surrounding venous plexus (ACV) [9]. The hypoglossal branch supplies the meninges of the posterior fossa and vasa nervorum of CN XII. It gives off meningeal branches, which extend upward along the clivus (clival branches), anastomosing with the corresponding medial clival branches of the MHT of the ICA. Because of this anastomosis, the neurohy- 
Table 1. Dangerous extracranial-intracranial anastomoses of the neuromeningeal trunk of the ascending pharyngeal artery

\begin{tabular}{|c|c|c|c|c|}
\hline \multicolumn{3}{|l|}{ Extracranial } & \multicolumn{2}{|l|}{ Intracranial } \\
\hline Artery & Branch & Foramen & Branch & Artery \\
\hline \multirow[t]{6}{*}{$\begin{array}{l}\text { Neuromeningeal } \\
\text { trunk }\end{array}$} & \multirow[t]{3}{*}{$\begin{array}{l}\text { Hypoglossal } \\
\text { branch }\end{array}$} & $\begin{array}{l}\text { Hypoglossal } \\
\text { canal }\end{array}$ & $\begin{array}{l}\text { Meningeal branches that extend as ascending clival } \\
\text { branches and anastomose with each other and with } \\
\text { medial clival branches of the MHT }\end{array}$ & $\begin{array}{l}\text { ICA } \\
\text { (C4 segment) }\end{array}$ \\
\hline & & \multirow{2}{*}{$\begin{array}{l}\text { Foramen } \\
\text { magnum }\end{array}$} & Prevertebral branch to odontoid arch (C1-C2 level) & VA \\
\hline & & & $\begin{array}{l}\text { Descending branch to vertebral branches that anas- } \\
\text { tomose with the ascending radiculomeningeal branch } \\
\text { to form the odontoid arch system (C3 level) }\end{array}$ & VA \\
\hline & \multirow[t]{3}{*}{ Jugular branch } & \multirow[t]{3}{*}{$\begin{array}{l}\text { Jugular } \\
\text { foramen }\end{array}$} & Lateral clival branches of the MHT & $\begin{array}{l}\text { ICA } \\
\text { (C4 segment) }\end{array}$ \\
\hline & & & $\begin{array}{l}\text { Anterior branches that anastomose with the lateral } \\
\text { clival branches of the inferolateral trunk }\end{array}$ & $\begin{array}{l}\text { ICA } \\
\text { (C4 segment) }\end{array}$ \\
\hline & & & $\begin{array}{l}\text { Sigmoid sinus branch that anastomose with: } \\
\text { (1) petrosquamosal branch of the middle meningeal } \\
\text { artery (MMA), (2) lateral tentorial artery of the MHT, } \\
\text { and (3) OA transosseous branches }\end{array}$ & MMA/ICA/OA \\
\hline
\end{tabular}

pophysis can sometimes be visible on lateral angiograms of the APhA. The hypoglossal branch contains $\mathrm{C} 1-\mathrm{C} 2$ muscular branches that anastomose with $\mathrm{C} 1-\mathrm{C} 2$ muscular branches of the VA. It also gives off a descending branch that anastomoses with the ascending C3 radiculomeningeal branch of the VA, contributing to form the so-called odontoid arch which supplies the first, second and third cervical roots and periostum of the spinous processes and pedicles [13]. The jugular branch supplies the vasa nervorum of CN IX, X, and XI, as well as the posterior fossa dura mater and the walls of the sigmoid and petrosal sinus. The jugular branch anastomoses with the more lateral, descending clival branches of the MHT [4]. Table 1 shows the dangerous extracranial-intracranial anastomosis between the neuromeningeal trunk of the APhA and the ICA or VA $[14,15]$.

The ACV originates from the anterior condylar confluence near the junction of the jugular bulb and the IPS and extends into the hypoglossal canal. The ACC has direct connections with the IJV, IPS, ACV, venous plexus of the ICA (via the inferior petro-occipital vein), and lateral condylar vein, all of which are venous channels devoid of valves, allowing for multidirectional venous flow. The ACV is the cranial extension of the AIVP.

The arterial supply to HCDAVFs is predominantly from the ipsilateral neuromeningeal trunk of the APhA, transmastoid branches of the $\mathrm{OA}$, meningeal branches of the VA, and clival branches of the MHT coming off the ICA. Sometimes, the vascular supply can be bilateral such as in our second case. Less frequently, these fistulas can be supplied by the internal maxillary artery, accessory meningeal artery, middle meningeal artery, and posterior auricular artery $[12]$.

\section{Treatment}

The target for a successful and safe embolization of HCDAVFs is the anterior condylar confluence or ACV which has multiple venous connections including AIVP, suboccipital 
venous plexus, posterior condylar vein, lateral condylar vein, suboccipital cavernous sinus, marginal sinus, IJV, cortical veins, and perimedullary veins, and retrogradely to the cavernous sinus and superior ophthalmic vein through the IPS $[2,4-6,16]$.

A transarterial embolization can potentially cure relieving some of the symptoms in a patient, but it is associated with higher risk of recurrence [2], cranial nerve palsy [17], or redirection of venous outflow from the fistula [9]. Ernst et al. [9] reported a case of a patient with ipsilateral proptosis and chemosis due to retrograde filling of the IPS and cavernous sinus to the superior ophthalmic vein that developed 2 years after transarterial embolization with polyvinyl alcohol of a HCDAVF. But the most concerning risk of transarterial approach is inadvertent embolization to the ICA or VA through extracranial-intracranial anastomoses causing cerebral infarction and/or lower cranial nerve palsy $[9,18]$ (Table 1).

According to Spittau et al. [12], three major types of venous drainage are associated with distinct clinical patterns: type 1, with anterograde drainage (62.5\%), mostly presents with pulsatile tinnitus; type 2, with retrograde drainage to the cavernous sinus and/or orbital veins $(23.3 \%)$, is associated with ocular symptoms and may mimic cavernous sinus DAVF; and type 3 , with cortical and/or perimedullary drainage (14.2\%), presents with either hemorrhage or cervical myelopathy. In our case series, all patients were type 1 HCDAVFs. For this type of fistulas, transvenous embolization represents an adequate treatment. According to Spittau et al. [12], transvenous embolization demonstrates high safety (permanent morbidity 2.9\%; mortality 0\%) and efficacy (angiographic occlusion 92.7\%).

The transvenous approach associated with coil embolization has been reported with excellent results $[1,2,5-7,9-11,19,20]$. The most direct route for the transvenous approach is through the IJV. The transvenous embolization leads to the highest rate of clinical cure at a relatively low therapeutic risk. There are some reports showing that overpacking the ACV may result in hypoglossal nerve palsy due to mass effect on the hypoglossal nerve as in our first case presented $[3,8,9]$. The damage to the hypoglossal nerve can be permanent $[3,8,18]$ or transient $[8,16,20]$.

Other materials can be used in conjunction or instead of coils for transvenous embolization, such as ethylene vinyl alcohol copolymer (Onyx). Takemoto et al. [16] reported 3 cases of transvenous embolization of a HCDAVF with Onyx that had excellent results. However, there are potential adverse effects associated with Onyx including direct neurotoxicity from dimethyl sulfoxide and retrograde reflux of Onyx into the feeding arteries $[16,18]$.

The largest review of the literature comes from Spittau et al. [12]; they showed a permanent morbidity of $16.7 \%$ and angiographic occlusion rate of $94.4 \%$ after transarterial embolization ( 2 hypoglossal nerve palsies after Onyx embolization and 1 brainstem infarction after n-BCA injection). The clinical cure rate was only 58.8\% compared to $91 \%$ after transvenous embolization. The combination of surgery with other treatment modalities (transarterial embolization) showed permanent morbidity of $13.3 \%$, angiographic occlusion rate of $90 \%$, and clinical cure rate of $73.3 \%$. Radiotherapy was very efficient with a permanent morbidity rate of $0 \%$ and angiographic occlusion rate of $100 \%$, but with a clinical cure in only $33 \%$ of the cases.

\section{Conclusion}

Transvenous embolization is a safe and effective approach to HCDAVFs and is associated with a low risk of complications and a high cure rate. A thorough knowledge of the anatomy and dangerous extracranial-intracranial anastomosis is paramount to avoid complications. Overpacking of the ACV may result in transient or permanent hypoglossal nerve palsy due to mass effect. 


\section{Interventional Neurology}

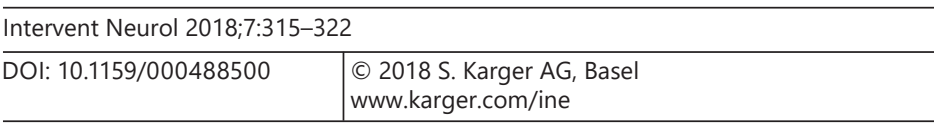

Santillan et al.: Embolization of Dural Arteriovenous Fistulas of the Hypoglossal Canal

\section{Statement of Ethics}

All subjects have given their informed consent, and the study protocol has been approved by the institute's committee on human research.

\section{Disclosure Statement}

There is no sponsorship or funding arrangements relating to our research. There are no conflicts of interest.

\section{References}

1 Okahara M, Kiyosue H, Tanoue S, Sagara Y, Hori Y, Kashiwagi J, et al: Selective transvenous embolization of dural arteriovenous fistulas involving the hypoglossal canal. Interv Neuroradiol 2007;13:59-66.

$\checkmark 2$ Choi JW, Kim BM, Kim DJ, Kim DI, Suh SH, Shin NY, et al: Hypoglossal canal dural arteriovenous fistula: incidence and the relationship between symptoms and drainage pattern. J Neurosurg 2013;119:955-960.

3 Manabe S, Satoh K, Matsubara S, Satomi J, Hanaoka M, Nagahiro S: Characteristics, diagnosis and treatment of hypoglossal canal dural arteriovenous fistula: report of nine cases. Neuroradiology 2008;50:715-721.

4 Miropolsky V, da Costa LB, Marotta TR, Spears J: Endovascular therapy of hypoglossal canal AVFs presenting with orbital symptoms. Can J Neurol Sci 2009;36:745-750.

5 Abiko M, Ikawa F, Ohbayashi N, Mitsuhara T, Ichinose N, Inagawa T: Endovascular treatment for dural arteriovenous fistula of the anterior condylar confluence involving the anterior condylar vein. A report of two cases. Interv Neuroradiol 2008;14:313-317.

-6 Arai Y, Ishii H, Handa Y, Ueda Y, Shirasaki N, Nozaki J, et al: Dural arteriovenous fistula within the hypoglossal canal successfully treated by transvenous embolization. Case Report. Interv Neuroradiol 2004;10:59-62.

7 Cyril C, Ofelia M, Herve D: Dural arteriovenous fistula involving the anterior condylar canal. J Neuroimaging 2013;23:425-428.

8 Miyachi S, Ohshima T, Izumi T, Kojima T, Yoshida J: Dural arteriovenous fistula at the anterior condylar confluence. Interv Neuroradiol 2008;14:303-311.

-9 Ernst R, Bulas R, Tomsick T, van Loveren H, Aziz KA: Three cases of dural arteriovenous fistula of the anterior condylar vein within the hypoglossal canal. AJNR Am J Neuroradiol 1999;20:2016-2020.

10 Kiyosue H, Tanoue S, Okahara M, Mori M, Mori H: Ocular symptoms associated with a dural arteriovenous fistula involving the hypoglossal canal: selective transvenous coil embolization. Case report. J Neurosurg 2001;94:630-632.

$\checkmark 11$ Chia GS, Lim WE: Anterior condylar confluence dural arteriovenous fistula: a rare cause of hoarseness. BM] Case Rep DOI: 10.1136/bcr-2016-218585.

-12 Spittau B, Millan DS, El-Sherifi S, Hader C, Singh TP, Motschall E, et al: Dural arteriovenous fistulas of the hypoglossal canal: systematic review on imaging anatomy, clinical findings, and endovascular management. J Neurosurg 2015;122:883-903.

13 Geibprasert S, Pongpech S, Armstrong D, Krings T: Dangerous extracranial-intracranial anastomoses and supply to the cranial nerves: vessels the neurointerventionalist needs to know. AJNR Am J Neuroradiol 2009; 30:1459-1468.

14 Lasjaunias P, Moret J: The ascending pharyngeal artery: normal and pathological radioanatomy. Neuroradiology 1976;11:77-82.

15 Lasjaunias P, Moret J, Mink J: The anatomy of the inferolateral trunk (ILT) of the internal carotid artery. Neuroradiology 1977; 13:215-220.

-16 Takemoto K, Tateshima S, Rastogi S, Gonzalez N, Jahan R, Duckwiler G, et al: Onyx embolization of anterior condylar confluence dural arteriovenous fistula. J Neurointerv Surg 2014;6:e13.

17 Cavalcanti DD, Reis CV, Hanel R, Safavi-Abbasi S, Deshmukh P, Spetzler RF, et al: The ascending pharyngeal artery and its relevance for neurosurgical and endovascular procedures. Neurosurgery 2009;65(6 suppl): 114-120; discussion 20.

18 Pei W, Huai-Zhang S, Shan-Cai X, Cheng G, Di Z: Isolated hypoglossal nerve palsy due to endovascular treatment of a dural arteriovenous fistula with Onyx-18. Interv Neuroradiol 2010;16:286-289.

-19 Hsu YH, Lee CW, Liu HM, Wang YH, Chen YF: Endovascular treatment and computed imaging follow-up of 14 anterior condylar dural arteriovenous fistulas. Interv Neuroradiol 2014;20:368-377.

-20 Kanemaru K, Yoshioka H, Yagi T, Wakai T, Hashimoto K, Fukumoto Y, et al: Hypoglossal canal dural arteriovenous fistula embolized under precise anatomical evaluation by selective intra-arterial injection computed tomography angiography. Interv Neuroradiol 2015;21:88-93. 